\title{
A Systematic Mapping Review of All-Learning Model of Integration of Educational Methodologies in the ICT
}

\author{
Gabriel M. Ramirez ${ }^{1(\&)}$, Cesar A. Collazos ${ }^{1}$, \\ and Fernando Moreira ${ }^{2,3}$ \\ ${ }^{1}$ Facultad de Ingenieria Electronica y Telecomunicaciones - FIET, \\ Universidad del Cauca, Cl. 5 \#470, Popayán, Cauca, Colombia \\ \{gmr,ccollazos\}aunicacuca.edu.co \\ ${ }^{2}$ Portucalense Institute for Legal Research - IJP, Universidade Portucalense, \\ Rua Dr. António Bernardino Almeida, 541-619, 4200-072 Porto, Portugal \\ fmoreiradupt.pt \\ ${ }^{3}$ IEETA, Universidade de Aveiro, Aveiro, Portugal
}

\begin{abstract}
Technology has had a positive impact in education, which has allowed education to evolve faster. This article presents a systematic mapping review of models and methodologies integrated with information and communication technologies. In the revision of the systematic mapping, 919 articles were found in 6 academic databases and 129 relevant articles were selected according to the defined inclusion patterns. This work pretends to characterize the common elements between models and educational methodologies to find ways to integrate them with the new technologies of information and communication.
\end{abstract}

Keywords: ICT• Model• Methodology•Integration • Education • Systematic mapping review

\section{Introduction}

There are currently different media technologies that apply to education, to develop learning processes mediated through information and communication technologies such as electronic learning (e-learning), mobile learning (m-learning), game learning (g-learning) and Ubiquitous Learning (u-learning) [1] which have become an important support for current educational processes, nowadays an education without ICT is not conceivable due to the impact and permeability of technology in all environments and areas of society [1].

Whenever there are new ICTs that may apply to the education is possible to develop new studies and research related to the impacts of technologies in educational processes [2]. In this case it is proposed to investigate in U-Learning relating the Connective Learning and the Learning Experiences or XAPI, from the pedagogical and technological perspective [2].

This paper presents a systematic review performed in the context [3] of a doctoral research project. This research proposes the design of a new model to U-Learning [5]. 

The systematic review is a literature search process to analyze, evaluate and interpret all relevant studies on a question or several research questions in particular, specific area or phenomenon of interest [3].

The methodology is used in this paper and the phases are presented below: planning the review, developing the review and generating the reports of the review [3, 4]. The paper is structured as follows: Sect. 2 explores the need for a systematic review in the area of the models that integrate the ICTs and the models, methodologies and educational strategies. Section 3 presents the methodology of the systematic review, the steps followed according to the methodology of Kitchenham [5] y Petersen [4], research questions, keywords, chosen databases, inclusion and exclusion criteria, queries, the search process and the extraction of data. Section 4 shows the results and the analysis of the data obtained in the systematic review. Section 5 discusses the conclusions and the future work.

\section{Review Necessity}

According to the World Bank's Learning for All [6], investment in people's knowledge and skills promotes the development of the world's population. One of the main goals of education at the global level has been to reduce the educational gap by bringing education to all people around the world [7].

This has led to a lag in education because while new students, mostly digital natives, are moving towards an interconnected education with multiple elements and devices, education continues to carry out educational processes aimed at digital migrant students $[8,9]$; the needs of the education of new students are different and they need pedagogical and technological models, strategies, methodologies and updated technological paradigms that allow to visualize the education of the future to apply it in the current education $[10,11]$.

The Inter-American Development Bank (IDB), Education for the 2012 Transformation, indicates that education must focus on quality, preparation for global scenarios and markets, and close the gap between education and the business world, it defines real needs and educate in skills to provide real solutions $[6,12]$.

\section{Systematic Mapping Review}

A systematic literature review is a method to analyze, evaluate and interpret all relevant studies to a particular research question, or specific area, or phenomenon of interest [13]. A systematic mapping review is a new version of this technique in which the evidence is represented in the results of the search and the analysis of data [5]. Kitchenham and Charters $[4,6]$ propose to use this methodology in the field of Software Engineering. The systematic review is a methodology that allows to make searches of information in a rigorous way, allows to analyze, evaluate and interpretstudies according to the specific research needs. In the systematic review, the methodology proposed by Kitchenham and Petersen [4, 5]. 
This systematic review methodology has been selected because it has all the necessary elements to carry out the search of information about the proposed topic. The importance of mapping the systematic review is found in the structure and steps it proposes to carry out the searches in an organized and methodological way which helps to generate reliable results in the investigations [4]. The process is detailed in Fig. 1.

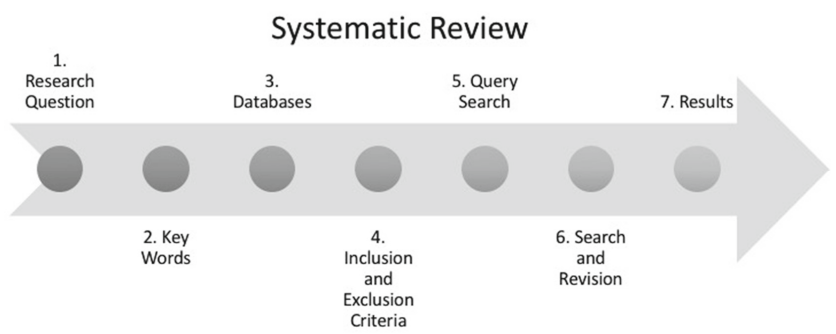

Fig. 1. Systematic review process

In the systemic review process [3], the following steps were followed: (1) two research questions were raised, (2) keywords were defined for searches in English, Portuguese and Spanish, (3) the databases to be consulted were defined, (4) the inclusion and exclusion criteria of articles were defined, as well as the range of time, (5) the advanced search strings were defined in each of the databases, (6) the process of search and revision of the articles was carried out, (7) new specific review, and (8) the results obtained in the review are presented.

\subsection{Research Questions}

The purpose of this work was determined by the current trends in information technologies applied to education and the need to update current educational models and methods to be applied in teaching processes. Problems have been identified in the application of new information technologies in education because current learning processes do not adequately shape students' knowledge and skills in the workplace [7]. Accordingly, the following questions have been raised.

RQ1: What models have integrated educational methodologies and the new ICTs? RQ2: What methodologies and ICTs have been integrated to generate models?

\subsection{Definitions}

To have greater clarity in the terms used in the paper, a table of concepts definition was made. The concepts are related to the search strings used in the systematic review. Table 1 presents the concepts and their definitions. 
Table 1. Definition of general concepts

\begin{tabular}{l|l}
\hline Word & Definition \\
\hline ICT & $\begin{array}{l}\text { Information and communications technology or technologies is an umbrella } \\
\text { term that includes any communication device or application, encompassing: } \\
\text { mobile devices, computer and network, hardware and software, and various } \\
\text { services and applications associated with them [1]. }\end{array}$ \\
\hline U-Learning & $\begin{array}{l}\text { U-Learning is the ubiquitous learning process that can be performed at any } \\
\text { time, place, device and context [13]. }\end{array}$ \\
\hline M-Learning & $\begin{array}{l}\text { M-Learning or mobile learning is the learning process that is performed using } \\
\text { mobile devices such as smart phones. Its main feature is mobility [8]. }\end{array}$ \\
\hline B-Learning & $\begin{array}{l}\text { B-Learning or Blended learning is a term increasingly used to describe the way } \\
\text { e-learning is being combined with traditional classroom methods and } \\
\text { independent study [8]. }\end{array}$ \\
\hline E-Learning & $\begin{array}{l}\text { E-Learning or e-learning is the process of learning that is done using the } \\
\text { internet and computers to access education [1]. }\end{array}$ \\
\hline
\end{tabular}

\subsection{Key Words}

For the systematic review, the search of 7 keywords in English, Spanish and Portuguese was defined, to include greater results of the searches and that allows to have a more complete review in the databases. These words are detailed in Table 2.

Table 2. Keywords for the searches in the databases in English, Portuguese and Spanish

\begin{tabular}{l|l|l}
\hline Ingles & Português & Español \\
\hline Methodology & Metodologia & Metodología \\
\hline Model & Modelo & Modelo \\
\hline Learning & Aprendizagem & Aprendizaje \\
\hline ICT & ICT & TIC \\
\hline Integrations & Integração & Integración \\
\hline Education & Educação & Educación \\
\hline Pedagogy & Pedagogia & Pedagogia \\
\hline
\end{tabular}

\subsection{Database}

We defined six (6) databases to perform the search for information according to the mapping of the systematic review. We chose these databases because they are the most internationally recognized in the area of engineering, computer science and education. These databases publish articles, conferences, book chapters and others. The databases are detailed in Table 3. 
Table 3. Databases used in the search

\begin{tabular}{l|l|l}
\hline Name & Link & Acronym \\
\hline IEEE Xplore & http://ieeexplore.ieee.org/Xplore/home.jsp & IEEE Xplore \\
\hline SCOPUS & http://www.scopus.com & SCOPUS \\
\hline Science direct & http://www.sciencedirect.com & Science Direct \\
\hline ACM & http://dl.acm.org & ACM \\
\hline Web of science & https://webofknowledge.com & WOS \\
\hline Google scholar & https://scholar.google.com & GS \\
\hline
\end{tabular}

\subsection{Inclusion and Exclusion Criteria}

The inclusion and exclusion criteria of the mapping of the systematic review were defined according to the themes that are in the project and to the research questions for the searches.

The inclusion criteria are: (1) Articles published between the years 2013-2016, (2) Articles published in conferences, congresses, journals and book chapters, (3) Articles written in English, Portuguese and Spanish, (4) Articles that are found in the databases detailed in the table of databases, and (5) Articles related to higher education, virtual education, models and methodologies integrated with information and communication technologies.

The exclusion criteria are: (1) Document not available for download, (2) Articles in languages other than English, Spanish or Portuguese, (3) Articles that are not focused on the integration of educational methodologies with information and communication technologies, and (4) Gray literature.

Once the basic inclusion and exclusion criteria were applied, we proceed to review the titles and abstract of each of the papers. With this initial review, we decided if the paper is initially included in the accepted articles. After this process, each paper is reviewed in general form, making a reading of the paper, to know if it helps to answer the questions posed in the systematic review.

\subsection{Query Search}

A general search string was defined based on the general concepts of the title of the search and that allowed to answer the raised research questions. For each of the databases, we reviewed how to perform advanced searches and created the search string for each one of these, allowing more specific results according to the key wordsraised. It should be clarified that some databases are searched by abstract, title independently, therefore in some databases were created two or three search chains.

The result of the general chain is as follows: ((" "methodolog*" OR "methodological") OR ("model*")) AND ("integrat*") AND ("educat*" OR "learn*" OR "pedagogical") AND ("ICT" OR ("information" AND "communications" AND "technology")) AND (publication year > 2013)) 


\subsection{Search Process}

The search process is performed by accessing the six defined databases (IEEE, ACM, SCOPUS, Web of Science, Science Direct and Google Scholar), in each of the databases the specific string was defined to perform advanced search, defined keywords and search criteria. We did not consider other studies or databases for the search, once the results obtained in each of the databases, we organized the data obtained in a general spreadsheet where all the data obtained from each one of the databases, was grouped by database and assigned a code to the database.

The information to organize the obtained information was the following: (a) date of search, (b) database code, (c) database, (d) search string, (e) title, and (f) abstract.

\subsection{Data Extraction}

Once all the information of the searches in the databases is unified in the spreadsheet created, 919 items were found in the databases, the review process is initiated. Firstly, a general review is performed to find the papers, chapter of books, etc., 184 articles were repeated, and this is originated by the different searches in the same databases by different search chains.

Following this is a review of the titles and abstract of the papers, this review took into account the inclusion and exclusion criteria, all information relevant to the planned search and that will help to answer the research questions initially raised. The general summary of the accepted papers is detailed in Fig. 2.

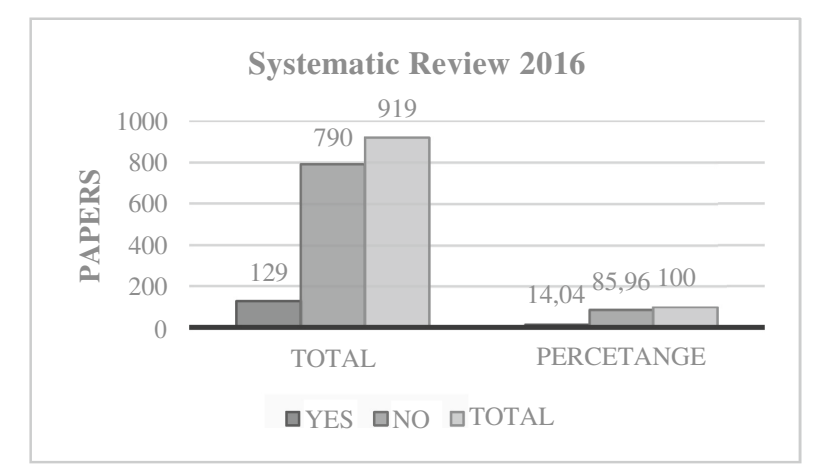

Fig. 2. Papers accepted in the systematic review

The papers included in the mapping of the systematic review were 129, which met the inclusion criteria and are relevant to answer the initial questions of the systematic review. These papers belong to the defined databases. The general summary of accepted and rejected papers by databases are detailed in Fig. 3 .

According to the information obtained in the mapping of the systematic review of articles obtained in the databases, 129 articles were accepted, 790 were not accepted 


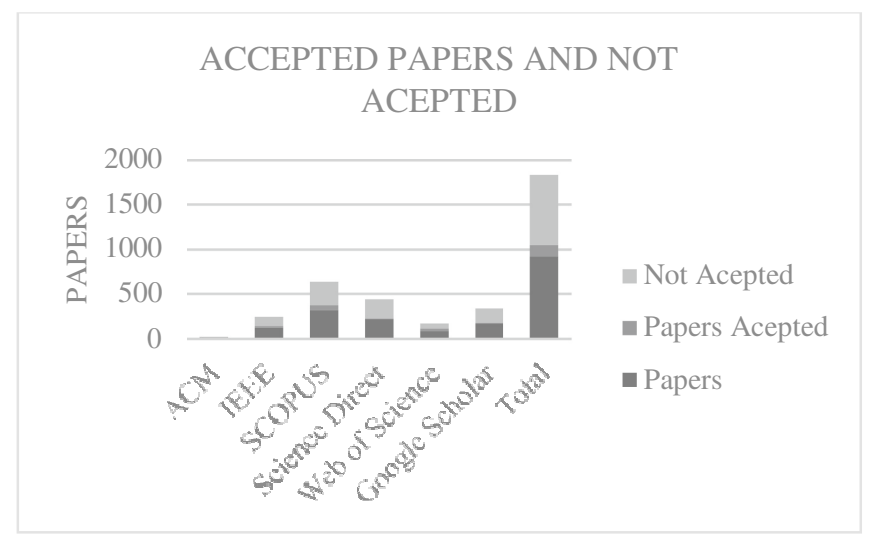

Fig. 3. Accepted and not accepted papers by database in the systematic review

and 184 articles were duplicated in the search results of the databases. The distribution of the papers according to the language in which it was written can be seen in Fig. 4 .

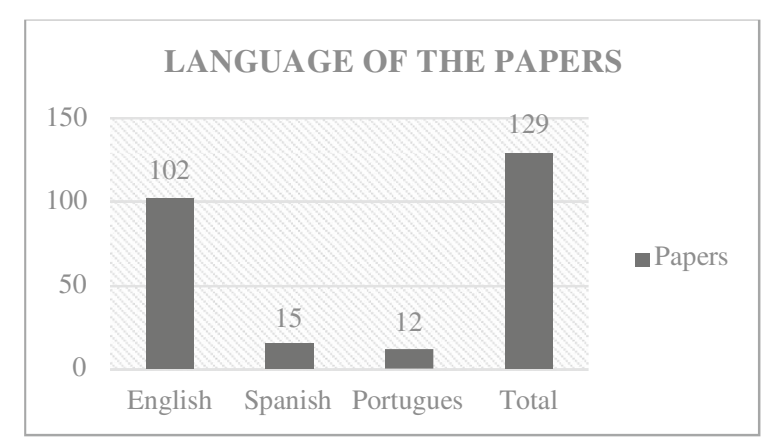

Fig. 4. Language of the papers accepted in the systematic review

\section{Data Analysis and Results}

Based on the 129 accepted papers in the mapping of the systematic review, most of them were found in Scopus, Web of Science and IEEE databases were 90\% of accepted papers are there. In the other databases (ACM, Science Direct and Google Scholar) is the remaining $10 \%$ of the systematic review.

In the systematic review, the results of the papers were classified according to the models, methodologies and the TIC. Table 4 presents the classification of papers (Fig. 5).

The results obtained in the systematic review allowed to obtain results related to the models, methodologies and strategies integrated with ICT. These results present a great variety of topics, The results are detailed in Fig. 6. 


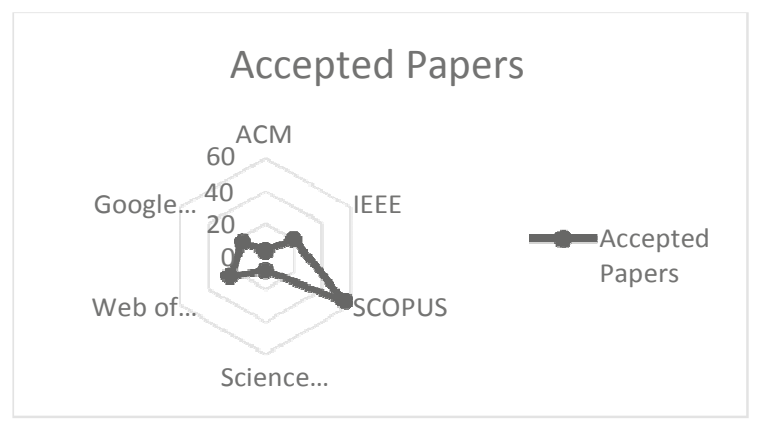

Fig. 5. Dispersion of the accepted papers

Table 4. Classification in the topical models, methodologies and ICT of the papers

\begin{tabular}{l|c|l}
\hline Topic & Papers & Percentage \\
\hline Integrated model & 38 & $29 \%$ \\
\hline Integrated methodology & 20 & $16 \%$ \\
\hline ICT & 71 & $55 \%$ \\
\hline Total & 129 & $84 \%$ \\
\hline
\end{tabular}

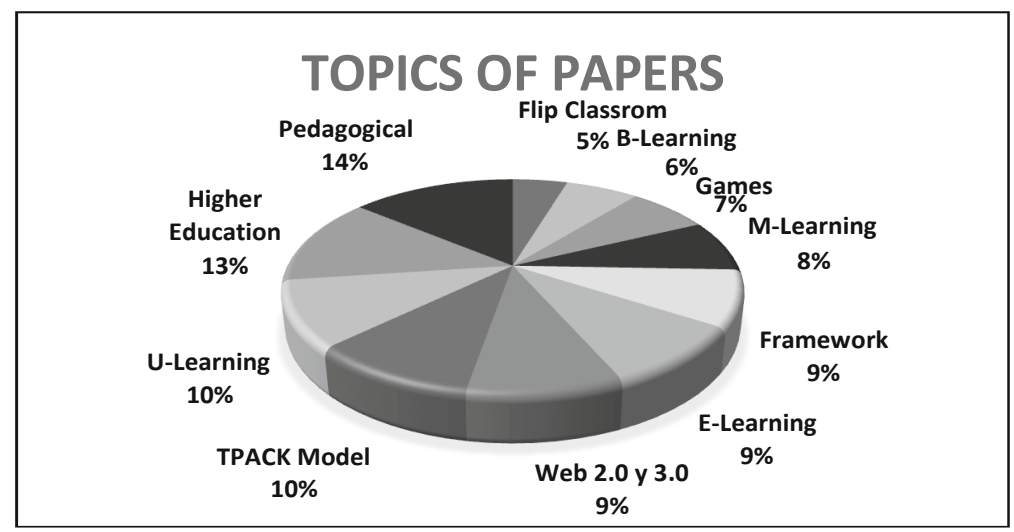

Fig. 6. Classifications of the topics papers

The papers found present different models that have integrated ICT with education. In the review, we found interesting models such as the TPACK which is a model that identifies the types of knowledge in ICT that a teacher must have to impart the teaching process effectively. In this same sense we can see the combination of pedagogical strategies in higher education supported by ICT, as well as the integration ofeducation technology with ICT through E-Learning, M-Learning and U-Learning [14]. 
The research questions initially raised in the systematic review are presented in the tables and figures above. The answers to the questions guide the research of the doctoral project to a new systematic review more specialized and specific. For each review question the answers were found.

RQ1: We found models that integrate educational strategies and ICT, these models are specific and there is no general model that defines an integration. The models most important in the systematic review are: TPACK Model, Mobile Learning and Technology Acceptance Model TAM, A Maturity Model for Assessing the use of ICT, The eSG Project: A Blended Learning Model for Teaching Entrepreneurship Through Serious Games, Development of Instructional Model Base on Connectivism Learning, E-Inclusion Modeling for Blended, social ecological model analysis for ICT integration, Ubiquitous Learning: teaching modeling and simulation with technology, A cloud model for effective e-learning, innovate web 2.0 based collaborative learning and study circle model, a hierarchical model for e-learning implementation challenges using AHP and A conceptual framework for enhancing the motivation in an open learner model learning environment, the flipped classroom model at the university

RQ2: We found methodologies that integrate educational strategies and ICTs in a specific way, however in the revision there is no methodology that defines the specific steps of how to integrate education and ICT. The methodologies most important in the systematic review are: An additional content development methodology in an adaptive agent based e-learning environment, The Evaluating of Integration of ICT in Higher Education: Foundation for a Methodology, Parallel virtual urban workshop: A 'reasonable-cost' methodology for academic internationalization in problem-solving oriented postgraduate subjects and Web 2.0 tools for role-play methodology in an undergraduate interdisciplinary environment

\section{Conclusions and Future Works}

The selected papers are the first part of the state art in the project of a doctoral research where the purpose to design a U-Learning model based on the experiences of learning and connective learning in virtual higher education $[13,15]$. This first part includes all the information relevant to the models, methodologies, strategies integrated with information and communication technologies, which are the theoretical basis of the integration model to be proposed in the U-Learning model [16].

According to the systematic review, no model was found that generally indicates the guidelines of how to integrate information and communication technologies with education focused on U-Learning [9], just models, methodologies and strategies were found for specific cases but not a general model that integrates ICT and connective learning $[17,18]$ into U-Learning [16]. 
The new systematic review will be focus on the topics of U-Learning, Connective Learning and Learning Experiences [19, 20], since they are the themes that will be taken as the basis of the integration model proposed in the research [13]. The integration will be made based on the integrated models and methodologies that were found in the systematic review carried out.

\section{References}

1. Behera, S.: E - and M-Learning: a comparative study. Int. J. New Trends Educ. Implic. 4, 65-78 (2013)

2. Kang, B.H., Kim, H.: Proposal: a design of u-learning module application for multi-cultural students in Korea. Int. J. Softw.Eng. Appl. 9, 167-172(2015). doi:10.14257/ijseia.2015.9.1.14

3. Kitchenham, B., Charters, S.: Guidelines for performing systematic literature reviews in software engineering. Engineering 2, 1051 (2007). doi:10.1145/1134285.1134500

4. Petersen, K., Feldt, R., Mujtaba, S., Mattsson, M.: Systematic mapping studies in software engineering. EASE 8, 68-77 (2008)

5. Kitchenham, B.A.: Systematic review in software engineering. In: Proceedings of 2nd International Work Evidential Assess Software Technology, EAST 2012, vol. 1 (2012). doi:10.1145/2372233.2372235

6. Cabrol, M., Székely, M.: Educación para la transformación. In: Acosta, A., Blanco, R., Eroles, D., Goldberg, M. (eds.) Banco Interam Desarro (2012)

7. Willcox, K.E., Sarma, S., Lippel, P.H.: Online Education: A Catalyst for Higher Education Reforms, vol. 39. MIT, Cambridge (2016)

8. Martín, S., Gil, R., Díaz, G., et al.: From e-learning to m-learning through b-learning and slearning

9. Oliveira, J.M., Rabello, S.A., Barbosa, J.L.V., Barbosa, D.N.F.: Uma Infraestrutura Descentralizada para Ambientes de Aprendizagem Ubíqua. Rev. Bras. Informática na Educ. 20, 85-99 (2012). doi:10.5753/RBIE.2012.20.03.85

10. Coto, M., Collazos, C.A., Rivera, S.M.: Modelo colaborativo y ubicuo para apoyar los procesos de enseñanza-aprendizaje a nivel iberoamericano. Rev. Educ a Distancia (2016). doi: $10.6018 / \mathrm{red} / 48 / 10$

11. Oliveira, L., Moreira, F.: Personal learning systems integration of web 2.0 apllications and content management systems. In: Proceedings of 11th European Conference Knowledge Management on ECKM 2010, pp. 11171-1177 (2012)

12. Zinny, G.S.: EDUCACION 3.0, Norma. Bogota (2015)

13. Gros, B., Kinshuk, Maina, M.: The Future of Ubiquitous Learning. LNET. Springer, Heidelberg (2016)

14. Herrera-Sánchez, D., Gutierrez-Vela, F.L., Paderewski-Rodríguez, P.: u-Learning Gamification : Gamificación aplicada a entornos ubicuos de enseñanza y aprendizaje. Congr Iberoam Ambient Aprendiz Futur 12 (2015)

15. de Lima, R.M., Guerra, L.T.B., Fiorin, A.: Educação Ubíqua: Um Modelo de Adaptação para o Moodle. Rev. Eletrônica Argentina-Brasil Tecnol. da Informação e da Comun., 1 (2015)

16. Martinez, H.A.V., Moreno, F.J.T., Miranda, C.A.L.: Aprendizaje ubicuo en la enseñanza de las matematicas. Rev. Estud. Cult. 5, 123-136 (2010)

17. Tumino, M.C., Adventista, U.: Conectivismo: Hacia El Nuevo Paradigma De La Enseñanza Por Competencias. Eur. Sci. J. 12, 112-129 (2016). doi:10.19044/esj.2016.v12n10p112 
18. Siemens, G., Onderwijsdagen, S., Age, D., et al.: Connectivism : a new learning theory ? (2006)

19. Vidal, J.C., Rabelo, T., Lama, M.: Semantic description of the Experience API Specification. In ICALT (2015). doi:10.1109/ICALT.2015.128

20. Serrano-Laguna, Á., Martínez-Ortiz, I., Haag, J., et al.: Applying standards to systematize learning analytics in serious games. Comput. Stand. Inter. 50, 16 (2016). doi:10.1016/j.csi. 2016.09.014 